\title{
Low-cement content gravity dam as an alternative for Pskem HPP
}

\author{
Nikolai Aniskin ${ }^{1}$, Alexey Shaytanov ${ }^{1 *}$, Mikhail Shaytanov ${ }^{2}$, and Sergei Khokhotva ${ }^{3}$ \\ ${ }^{1}$ Moscow State University of Civil Engineering, Yaroslavskoe shosse, 26, Moscow, 129337, Russia \\ ${ }^{2}$ SDEB "Moshydrostal" branch of the "Trest Gidromontazh" JSC, 123007, Moscow, \\ Karamyshevskaya nab., 37, Russia \\ ${ }^{3}$ Self-employed researcher
}

\begin{abstract}
In this paper, we consider the numerical justification of the possibility to construct a low-cement content concrete gravity dam as an alternative to the traditional solution with a rockfill dam in a Pskem HPP canyon on the river Pskem in Uzbekistan Republic. The calculation studies were performed using the finite element method (FEM), considering the non-linear (elastoplastic) behavior of concrete and foundation rock in the ANSYS software package. Seismic stability of structure was ascertained by means of time-dependent transient dynamic analysis in accordance with the implicit temporal scheme, since such approach allows to trace the development of plastic deformations in the structure and foundation during dynamic loading as well as to evaluate the possible adverse effects. Maximum design earthquake bicomponent accelerogram was involved as an input data for seismic stability analysis. According to the results of the study the conclusions were made about the possibility of construction of a high low-cement content concrete dam in geotechnical, hydrological and climatic conditions of the Pskem HPP site on the Pskem River as well as on the other HPPs of the Chirchik-Bozsu cascade in Uzbekistan Republic, which are now under design. The reported study was funded by RFBR, project number 20-38-90160.
\end{abstract}

\section{Introduction}

At present time there are more than 800 low-cement content concrete dams in the world, ranging in height from $15 \mathrm{~m}$ to $250 \mathrm{~m}$ (Gilgel Gibe III dam in Ethiopia). Relative simplicity, high intensity of layer-by-layer buildup of structures and the associated costeffectiveness of projects due to reduced construction time, the amount of cement supplied to the construction site as well as reduced requirements for concrete mix, determine a continuous increase in the number of dams built using this technology [1,2].

The construction site of the Pskem HPP will be located on the Pskem river in Bostanlyk district of Tashkent region (Uzbekistan Republic), $120 \mathrm{~km}$ north-east from Tashkent and 50 $\mathrm{km}$ from the existing Charvak HPP (Fig. 1).

*Corresponding author: shaytanov.alexey@mail.ru 
a)

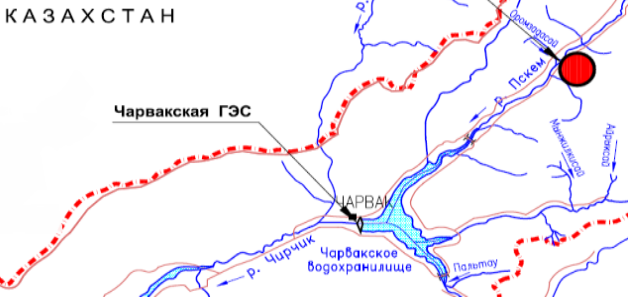

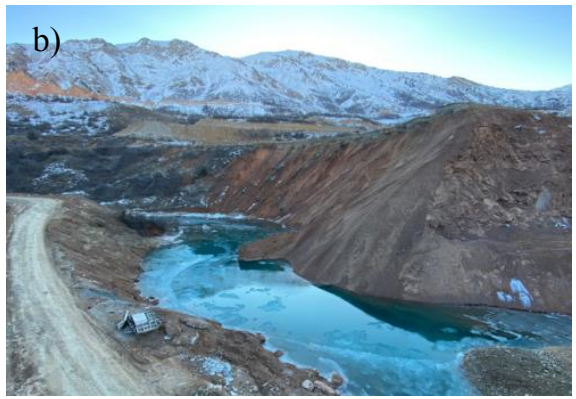

Fig. 1. Pskem HPP construction site: a) Location of the HPP relative to the existing Charvak HPP; $b$ ) chosen construction site

The Pskem River basin $\left(\mathrm{F}=2,810 \mathrm{~km}^{2}, \mathrm{~L}=73 \mathrm{~km}\right)$ is located in the Western Tien Shan Mountains and bounded by the Talas, Pskem, and Ugam ridges, with average elevations varying from 2,000 $\mathrm{m}$ to 4,400 $\mathrm{m}$ and decreasing from the source to the mouth. In the basin there are up to 140 glaciers with a total area of $129 \mathrm{~km}^{2}$, the average height of the firn line of the Pskem River is in the range of $3600 \mathrm{~m}-3720 \mathrm{~m}$. The main structures of the complex are located at elevations of $1100 \mathrm{~m}-1200 \mathrm{~m}$. Seismicity of the construction area is 9 points magnitude $[3,4]$.

Total installed capacity of the hydropower plant according to the project will be 400 MW, annual power generation - more than 958.3 million $\mathrm{kWh}$. As a result of HPP construction, Pskem reservoir of seasonal flow regulation with full capacity of 511.2 million $\mathrm{m} 3$ and usable capacity of 476.2 million $\mathrm{m}^{3}$ will be formed.

Currently, the General designer of the project, JSC "Hydroproject" has considered a 197 $\mathrm{m}$ high rockfill dam with the main impervious element of a clay core or reinforced concrete screen as a major variant.

The authors of the article offer an alternative version of the high dam of the Pskem HPP made of low-cement content concrete as well as calculation justification, considering the stage of construction, sediment pressure and seismic exposure [3-6].

To ensure high reliability of the structure in difficult geological, climatic and seismic conditions, it was considered to involve the main impervious geocomposite liner, which consists of PVC sheets with an effective thickness of $4,0 \mathrm{~mm}$ heat-bonded with needlepunched non-woven polypropylene geotextile with $700 \mathrm{~g} / \mathrm{m}^{2}$ surface density. The solution is based on the long-term successful experience of involving such systems on similar projects around the world (more than $40 \mathrm{dams}$ ). The key benefits are the following [7-9]:

- Cost reduction for additional preparation and treatment of joints.

- No need to construct a vibrated concrete upstream wall or a special zone with a higher cement consumption RCC.

- High elasticity of the geocomposite liner (elongation at failure is more than $250 \%$ ) and capability to accommodate any kind of dam body settlements allow to temperature cracking and, consequently, enhance placement intensity that will reduce construction time.

- Ease of installation and monitoring of the exposed geocomposite waterproofing system.

Nowadays, the best-known material is the SIBELON CNT geocomposite invented by swiss company Carpi Tech SA, which stress-strain properties were considered in the present study (Fig. 2). 


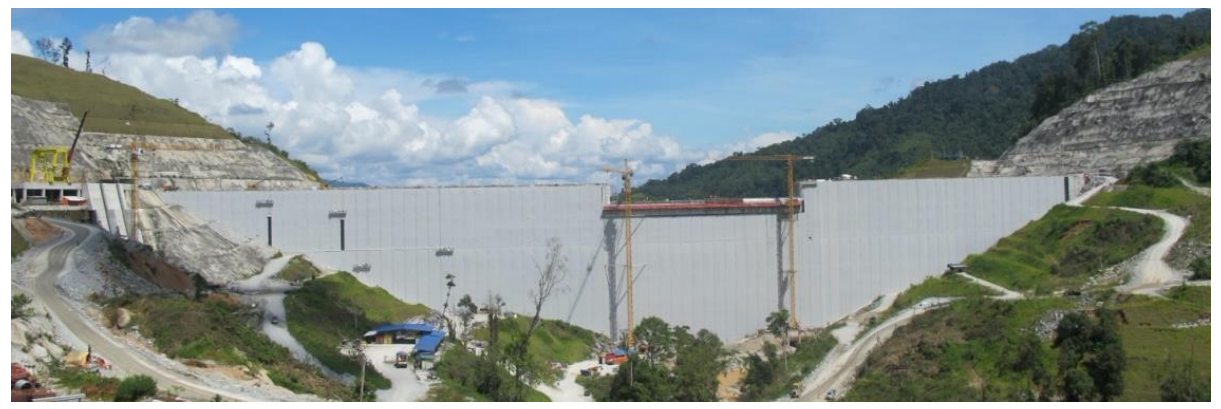

Fig. 2. SIBELON CNT exposed geocomposite system installed at Susu low cement content concrete dam, Malaysia, 2016

According to the ICOLD (International Committee on Large Dams) data, as of 2010, geocomposite impervious systems have been installed on more than 160 different types of dams, demonstrating their high reliability and efficiency [7].

\section{Methods}

The parameters and design of the channel section of the proposed gravity dam as well as the FEM model of the «dam-foundation» are presented on Fig. 3.
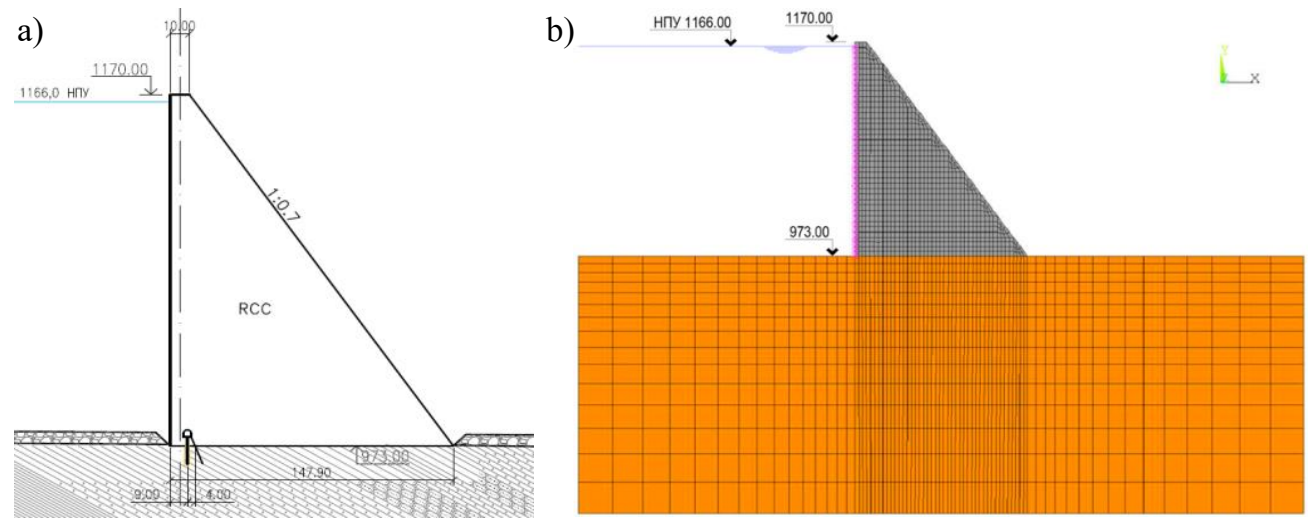

Fig. 3. Channel section of the Pskem low cement content concrete dam, where: a) cross section, b) finite element model of the «dam-foundation» system

At the foundation of the structure are Neogene age siltstones, the geomechanical characteristics of which are shown in the Table 1.

Table 1. Main geomechanical characteristics of the dam foundation rock

\begin{tabular}{|c|c|c|c|c|c|c|c|}
\hline Type of foundation rock & Zone & $\begin{array}{c}\text { Density } \\
\rho, \mathrm{t} / \mathrm{m}^{3}\end{array}$ & $\begin{array}{c}\text { Friction } \\
\text { angle } \varphi, \\
\text { degree }\end{array}$ & $\begin{array}{c}\mathrm{C}, \\
\mathrm{MPa}\end{array}$ & $\begin{array}{c}\mathrm{R}_{\text {compr. }} \\
\mathrm{MPa}\end{array}$ & $\begin{array}{c}\mathrm{E}_{\text {def, }}, \\
\mathrm{MPa}\end{array}$ & $\begin{array}{c}\text { Poisson's } \\
\text { ratio }\end{array}$ \\
\hline $\mathbf{1}$ & $\mathbf{2}$ & $\mathbf{3}$ & $\mathbf{4}$ & $\mathbf{5}$ & $\mathbf{6}$ & $\mathbf{7}$ & $\mathbf{8}$ \\
\hline \multirow{2}{*}{ Siltstones } & I & \multicolumn{7}{|c|}{ To be removed } \\
\cline { 2 - 9 } & II & 2.39 & 42.0 & 0.3 & 9.0 & 5200 & 0.41 \\
\hline
\end{tabular}


A combined Drucker-Prager \& Rankine Concrete two-surface model was implemented to evaluate the behavior of the basement rocks within the study (1) [10-12]:

$$
f_{D P_{t}}=\frac{\sigma_{e}}{\sqrt{3}}+\beta_{t} \cdot \sigma_{m}-\sigma_{Y_{t}},
$$

where: $\sigma_{e}$ - equivalent stress, $\mathrm{MPa} ; \sigma_{\mathrm{m}}$ - hydrostatic pressure stress, $\mathrm{MPa}(2) ; \beta_{\mathrm{c}}$ и $\sigma_{\mathrm{Y}_{\mathrm{c}}}$ - material constants; $\Omega_{c}$ - hardening rule function.

$$
\sigma_{\mathrm{m}}=\frac{\sigma_{11}+\sigma_{22}+\sigma_{33}}{3}
$$

The material constants are described through uniaxial tensile strength (Rt) and compressive strength (Rc) by means of equations (3) and (4) respectively:

$$
\begin{aligned}
& \beta_{t}=\frac{\sqrt{3} \cdot\left(R_{c} \cdot \Omega_{\mathrm{c}}-R_{t} \cdot \Omega_{\mathrm{t}}\right)}{R_{c} \cdot \Omega_{\mathrm{c}}+R_{t} \cdot \Omega_{\mathrm{t}}} ; \\
& \sigma_{Y_{t}}=\frac{2 \cdot R_{c} \cdot \Omega_{\mathrm{c}} \cdot R_{t} \cdot \Omega_{\mathrm{t}}}{\sqrt{3} \cdot\left(R_{c} \cdot \Omega_{\mathrm{c}}+R_{t} \cdot \Omega_{\mathrm{t}}\right)},
\end{aligned}
$$

where: $\Omega_{\mathrm{c}}, \Omega_{\mathrm{t}}$ - hardening rule functions, which can be described through stresses and strain-hardening coefficients $\mathrm{k}$, characteristic point $\Omega_{i}$ as well as though other specific parameters.

Drucker-Prager yield potential for material in tensile condition can be determined in accordance with (5):

$$
Q_{D P_{t}}=\frac{\sigma_{e}}{\sqrt{3}}+\delta_{t} \cdot \beta_{t} \cdot \sigma_{m}
$$

where: $\delta_{t}$ - tensile dilatancy parameter.

Drucker-Prager yield potential for material in compressed condition can be determined in accordance with (6):

$$
Q_{D P_{c}}=\frac{\sigma_{e}}{\sqrt{3}}+\delta_{c} \cdot \beta_{c} \cdot \sigma_{m}
$$

where: $\delta_{c}$ - compression dilatancy parameter.

Drucker-Prager yield surface can be ascertained by the equation (7):

$$
f_{D P_{\mathrm{c}}}=\frac{\sigma_{e}}{\sqrt{3}}+\beta_{\mathrm{c}} \cdot \sigma_{m}-\sigma_{Y_{\mathrm{c}}} \cdot \Omega_{\mathrm{c}},
$$

where: $\beta_{\mathrm{c}}, \sigma_{Y_{\mathrm{c}}}-$ material constants $(8,9)$ :

$$
\begin{aligned}
\beta_{c} & =\frac{\sqrt{3} \cdot\left(R_{b}-R_{c}\right)}{2 \cdot R_{b}-R_{c}} ; \\
\sigma_{Y_{c}} & =\frac{R_{b} \cdot R_{c}}{\sqrt{3} \cdot\left(2 \cdot R_{b}-R_{c}\right)},
\end{aligned}
$$

where: $R_{c}$ - uniaxial ultimate compressive strength, $\mathrm{MPa} ; R_{b}-$ biaxial ultimate compressive strength, MPa.

Thus, to describe the behavior of the material using Drucker-Prager \& Rankine Concrete two-surface model in ANSYS software it is required to set the three following parameters:

$R_{c}$ - uniaxial compressive strength;

$R_{b}$ - biaxial compressive strength, $R_{b}=1,2 \cdot R_{c}$;

$R_{t}-$ uniaxial tensile strength.

The $R_{c}$ was considered as an $80 \%$ from the temporary compressive strength (10):

$$
R_{\mathrm{c}}=0,8 \cdot R_{\text {сж }}
$$

The $R_{t}$ can be ascertained by (11):

$$
R_{t}=2 \cdot C \cdot \tan \left(45-\frac{\varphi}{2}\right)
$$


where: $\varphi$ - bedrock internal friction angle (Table 1), $C$ - bedrock soil adhesion (Table 1). Consequently, the parameters of the bedrock material model were assumed to be as follows: $R_{\mathrm{c}}=7,20 \mathrm{MPa} ; R_{b}=8,64 \mathrm{MPa} ; R_{t}=0,267 \mathrm{MPa}$.

Concrete behavior model was also described by means of Drucker-Prager \& Rankine Concrete two-surface model [10-15]. The main characteristics of the low cement content concrete of the dam body are presented in Table 2 .

Table 2. Stress-strain properties of the low cement content concrete

\begin{tabular}{|c|c|c|c|c|c|}
\hline Concrete & $\begin{array}{c}\text { Density } \rho, \\
\mathrm{t} / \mathrm{m}^{3}\end{array}$ & $\begin{array}{c}\text { Compressive } \\
\text { strength } \mathrm{R}_{\mathrm{c}}, \\
\mathrm{M \Pi}\end{array}$ & $\begin{array}{c}\text { Tensile } \\
\text { strength } \mathrm{R}_{\mathrm{t}}, \\
\mathrm{MPa}\end{array}$ & $\mathrm{E}, \mathrm{MPa}$ & $\begin{array}{c}\text { Poisson's } \\
\text { ratio }\end{array}$ \\
\hline $\mathbf{1}$ & $\mathbf{2}$ & $\mathbf{3}$ & $\mathbf{4}$ & $\mathbf{5}$ & $\mathbf{6}$ \\
\hline $\begin{array}{c}\text { Low cement content } \\
\text { concrete }\end{array}$ & 2.50 & 7.50 & 0.66 & 22750 & 0.18 \\
\hline
\end{tabular}

The parameters of the concrete material model: $R_{\mathrm{c}}=7,50 \mathrm{MPa} ; R_{b}=9,00 \mathrm{MPa}$; $R_{t}=0,66 \mathrm{MPa}$.

The following loads were considered: own weight of the structure, hydrostatic pressure of water on the upstream face of the dam, sediment pressure, back pressure of filtered water on the bottom of the structure under different operation modes, seismic exposures [3-6].

Viscoelastic boundary conditions for the normal direction were set on the lateral boundaries of the base block, and viscoelastic boundary conditions for the normal and tangential directions were set on the lower boundary [10-12].

\section{Results}

The construction of the dam was planned in 18 stages $(0$ - natural stress-strain state of the foundation; 15 - reservoir filled up to el. 1166.00). Moreover, there were two extra cases, which were taken into account (16 - maximum design earthquake exposure; 17 emergency case when cement grout curtain and drainage were out damaged and out of operation. Results of the calculation will be revealed additionally).

Visualization of the history of the construction of the dam as well as filling of the reservoir is presented on Fig. 4. 


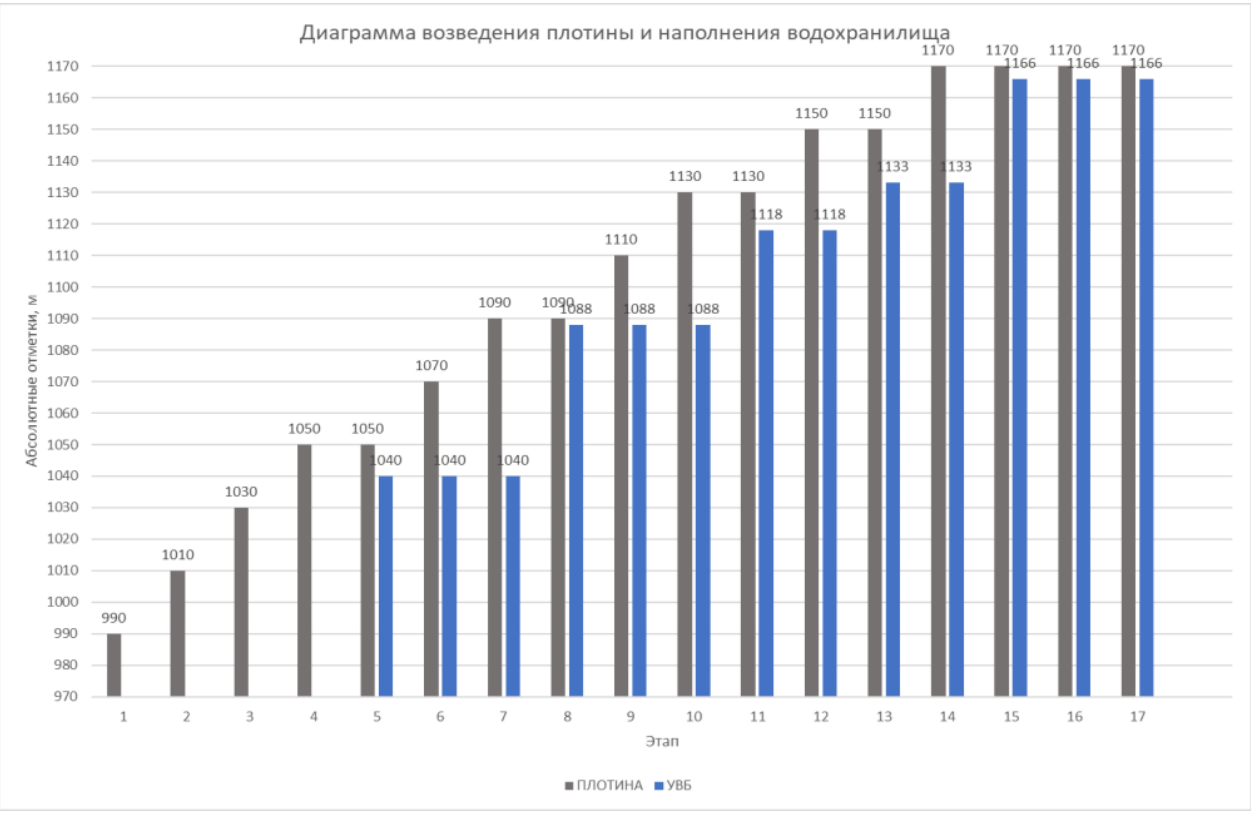

Fig. 4. History of the construction of the dam and filling of the reservoir

After the dam was risen up to the design elevation and reservoir was filled up to NWL seismic resistance calculations with transient dynamic analysis were performed for given earthquake accelerogram [3-5, 16-18].

After the end of the seismic exposure, the calculation in the time domain continues to assess the trend toward stabilization of displacements and deformations in the calculation domain [11].

In accordance with the requirements of the national standard of the Republic of Uzbekistan [3] for the structures of the I reliability class, the calculations should be made for seismic effects corresponding to the maximum intensity of earthquakes with a recurrence of once in 10000 years (exceedance probability of $0.01 \%$ ).

Numerical studies of the Pskem HPP dam stress-strain behavior were performed by the finite element method using transient dynamic analysis in time according to the implicit time scheme proposed by Newmark [10-12].

The maximum absolute peak acceleration of the horizontal impact component is 3.609 $\mathrm{m} / \mathrm{s} 2$, the vertical impact component is $1.947 \mathrm{~m} / \mathrm{s} 2$.

To perform transient calculations, it is required to set Rayleigh damping coefficients. Rayleigh damping is expressed through the linear combination of mass and stiffness matrices (12):

$$
[C]=\alpha \cdot[K]+\beta \cdot[M],
$$

where: $\alpha$ - mass proportionality factor, $\beta$ - stiffness proportionality factor (Fig. 5). 


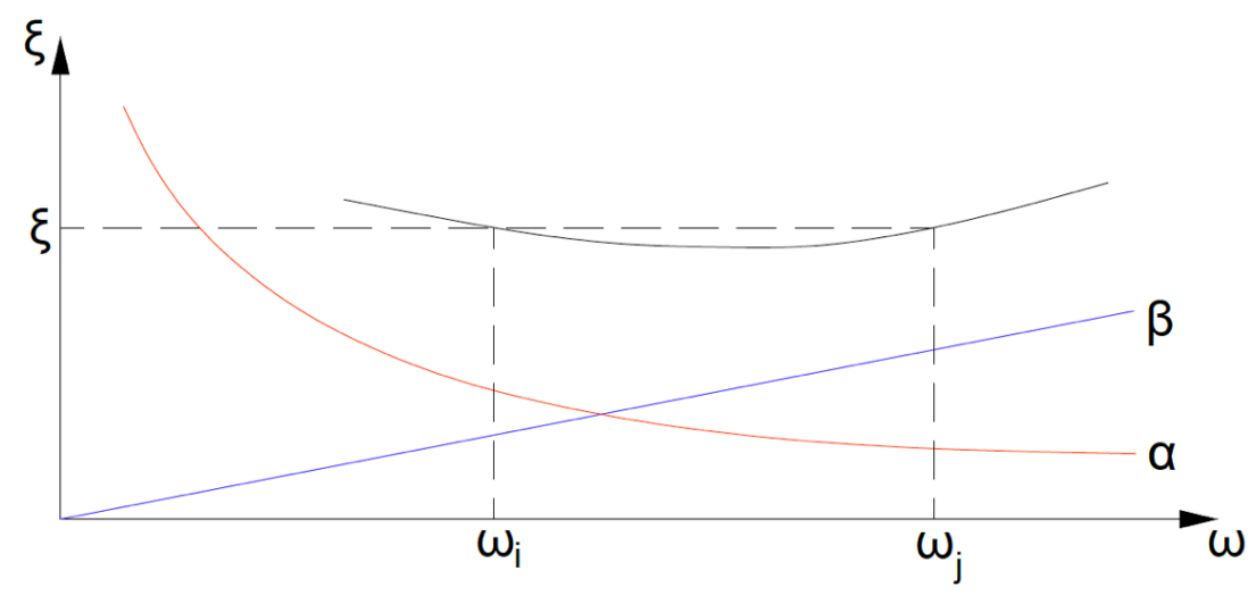

Fig. 5. Rayleigh damping coefficients, where: $\omega$ - oscillation frequency of the structure, $\mathrm{Hz} ; \xi-$ overall damping coefficient

Damping coefficients $\alpha$ and $\beta$ were determined under the condition that the overall damping coefficient $\xi$ in the frequency range from the frequency of the lowest form of oscillation of the structure ( $\mathrm{rad} / \mathrm{s})$ to the frequency of the upper limit of the seismic range $(\mathrm{rad} / \mathrm{s})$ remained constant.

For the Pskem HPP dam with the crest elevation of 1170.00 , the frequency of the lowest form of oscillation was $\omega_{\text {low }}=0,804 \mathrm{~Hz}$, the frequency of the upper limit of the seismic range $\omega_{\text {up. }}=10,0 \mathrm{~Hz}$, which was related to $95 \%$ of the overall effective modal mass of the structure (Fig. 6).

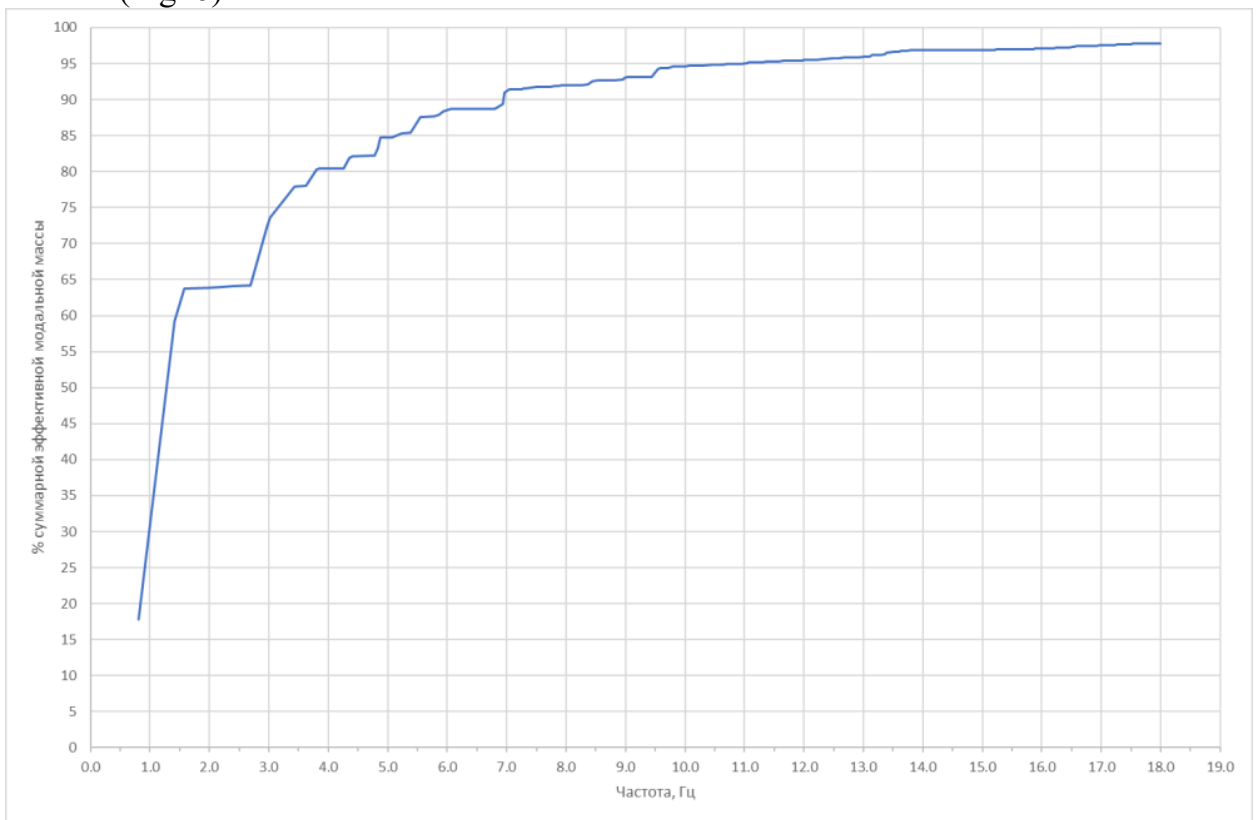

Fig. 6. Effective modal mass gain schedule

Overall damping coefficient $\xi$ for concrete dams is $\xi=0,05$, Rayleigh damping coefficients $\alpha=0,46735, \beta=0,0014732$. 
Based on the initial data presented above, calculations of the structure in question were made for the impact of the basic combination loads [5]. Horizontal displacement of the dam crest along the $\mathrm{X}$ axis is $11.4 \mathrm{~cm}$, vertical $-5.7 \mathrm{~cm}$.

Plastic deformations zones of the dam had local character of concentrations (connection of the downstream face with the foundation) with the value of equivalent plastic deformations not exceeding $0.06 \%$ (point-concentrator). As a rule, at the interface of the upstream face with the foundation, a vault device is usually made, which allows to avoid formation of stress concentration zone and reduce occurrence of plastic deformations.

Results of seismic exposure calculations using direct dynamic analysis in time are presented in the form of graphs of displacement increments in control points at the crest, downstream slope and bottom of the dam (Fig. 7), as well as in the form of isofields of plastic deformations in the dam and foundation.

a)

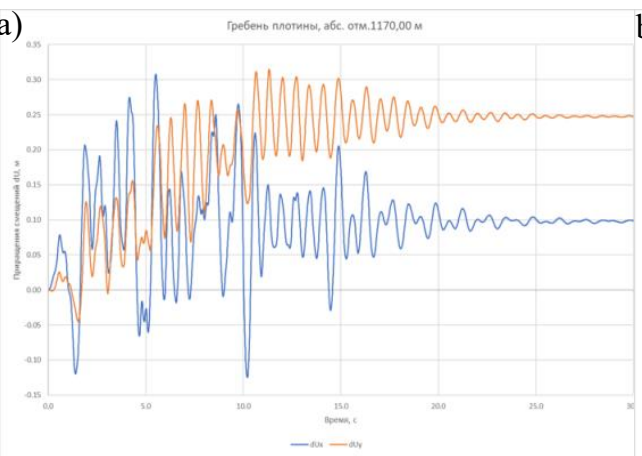

b)

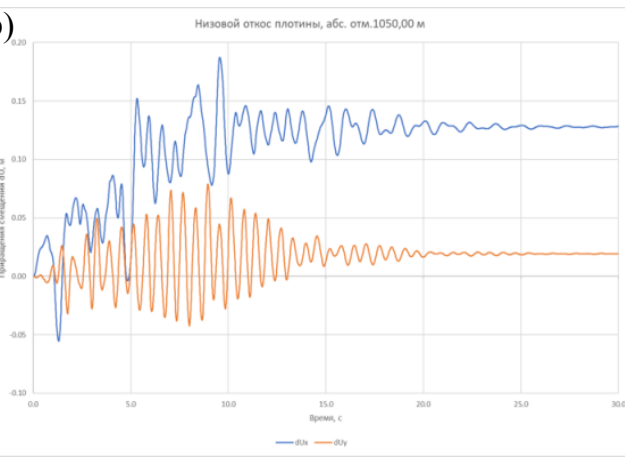

Fig. 7. Diagram of incremental displacements under seismic action: a) dam crest at el. 1170.00; b) downstream slope at el. 1050.00

According to the calculation results, in accordance with the graphs in Fig. 7, complete damping of the oscillatory process occurs 10-12 seconds after the earthquake (at 25-27 seconds of calculation). Then there is complete stabilization of displacements, which indicates the ability of the structure to absorb the given level of seismic action.

Peak maximum and minimum increments of horizontal displacements are fixed at the crest of the dam and at the reference point at the elevation $1130.00 \mathrm{~m}$ and reach values of $+32.9 \mathrm{~cm}$ (downstream side) and up to $-12.5 \mathrm{~cm}$ (upstream side) relative to static state. Peak deviations were recorded at time points of $5.51 \mathrm{~s}$ and $10.2 \mathrm{~s}$. Vertical increments of oscillations at $1170.00 \mathrm{~m}$ and $1130.00 \mathrm{~m}$ ranged from $-4.5 \mathrm{~cm}$ to $+31.5 \mathrm{~cm}$.

Maximum residual horizontal increments are fixed at elevation $1130.00 \mathrm{~m}$ and are $+22.6 \mathrm{~cm}$, vertical at the crest of the dam up to $+24.7 \mathrm{~cm}$. At the downstream slope elevation of $1050.00 \mathrm{~m}$ the residual horizontal displacement increments are $+18.7 \mathrm{~cm}$.

After seismic impact, there are extensive zones of plastic deformations in the dam body (Fig. 8). In the upper zone of the structure within $1110.00-1145.00 \mathrm{~m}$ elevation on the downstream face a zone of tensile horizontal plastic deformations up to $0,26 \%$ is formed, not reaching the upstream face by $15 \mathrm{~m}$ (Fig. 8). 
a)

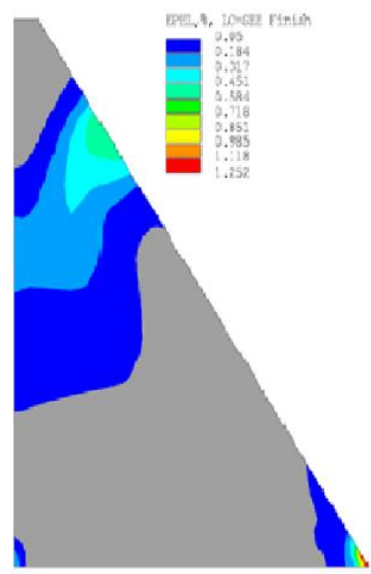

b)

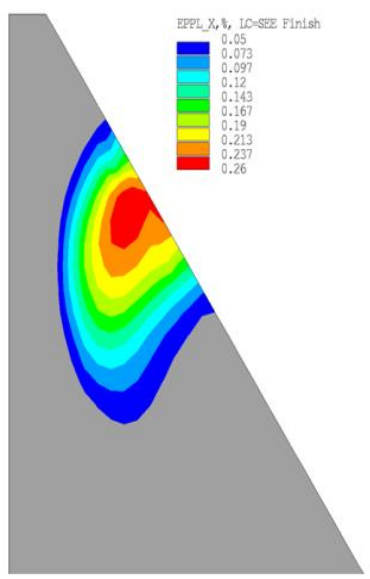

c)

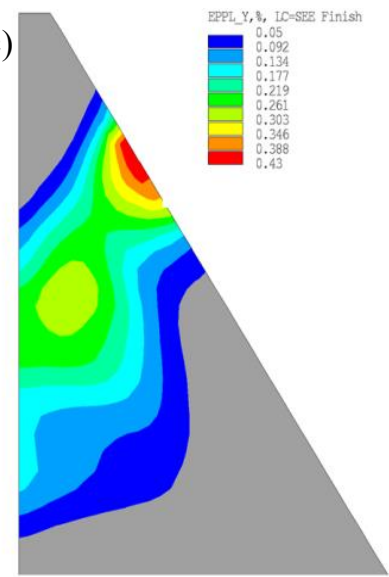

Fig. 8. Impact of the maximum design earthquake: a) equivalent plastic deformations of the dam; b) horizontal plastic deformations of the dam; c) vertical plastic deformations of the dam

The maximum vertical deformation in the upper part of the structure reaches $0.43 \%$, with the formation of a through zone of tensile plastic deformations from the top to the bottom face within the marks on the bottom face $1105.00-1145.00 \mathrm{~m}$, on the top face $1030.00-1110.00 \mathrm{~m}$. In the range of top face elevations $1072.00-1095.00 \mathrm{~m}$ and bottom face elevations $1112.00-1140.00 \mathrm{~m}$, vertical plastic deformation in the through zone exceeds $0.21 \%$. Formation of the through zone of horizontal cracks may lead to unfavorable filtration processes. In connection with the possible development of unfavorable scenario of cracking in the project initially provided for the device of impervious element geocomposite liner with an effective thickness of $4.0 \mathrm{~mm}$ on the upstream face of the structure.

Fig. 9 shows isofields of plastic deformations in the base of the structure after the oscillatory process has stabilized. An extensive zone of vertical tensile plastic deformations over $0.1 \%$ occurs in the contact zone with the base up to $15 \mathrm{~m}$ deep and up to $70 \mathrm{~m}$ long ( $47 \%$ of the contact area).
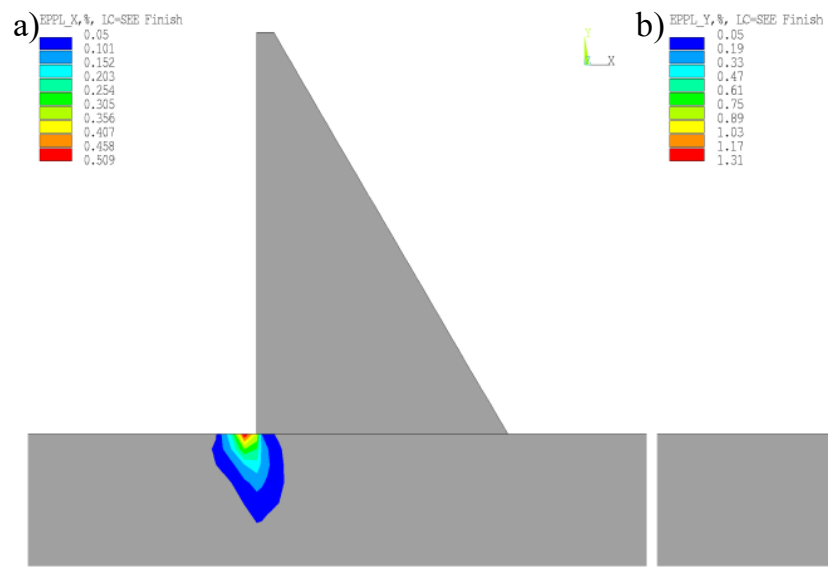

Fig. 9. Impact of the maximum design earthquake: a) horizontal plastic deformations of the foundation; b) vertical plastic deformations of the foundation

According to the results of the calculation, we can conclude that during the seismic impact of the maximum design earthquake level of 9 points magnitude in the structure can occur significant damage. 
The calculations results show stable convergence during and after the completion of seismic action. There is no progressive avalanche-like growth of displacements and deformations in the structure, which testifies to the ability of the structure to accept the given level of loads $[3,4,6,11]$.

Further the question of dam stability under static and dynamic influences was considered.

In accordance with the requirements of existing in the territory of the Republic of Uzbekistan KMK 2.06.06-98 [15] and KMK 2.06.01-97 [19], as well as SP 58.13330.2019 [20], the criteria for ensuring the stability of structures I class are defined by the ratio (13):

$$
\gamma_{n} \cdot \gamma_{l c} \cdot F \leq \gamma_{c d} \cdot R
$$

where: $F$ - generalized force effect; $\gamma_{n}$ - responsibility safety factor $(1,25) ; \gamma_{l c}-$ loads combination factor (1,0 for basic load combination and 0,9 for special load combination); $\gamma_{c d}-$ coefficient of working conditions, when calculating the stability of concrete and reinforced concrete dams on half-rock foundations taken equal to $1.0 ; R$ - overall carrying capacity.

Coefficient of stability against sliding on the «dam - foundation» contact can be determined by means of equation (14):

$$
\mathrm{K}_{s t}=\frac{\sum\left(F_{\text {hold }} \cdot \tan \varphi+C \cdot S\right)}{\sum F_{\text {slide }}},
$$

where: $F_{\text {hold }}$ - restraining forces; $F_{\text {slide }}$ - sliding forces; $\tan \varphi$ - «dam - foundation» contact friction coefficient; $C-\ll \mathrm{dam}$ - foundation» contact adhesion $[15,19,20]$.

The calculation results are presented in Table 3. According to them, for all design combinations, the sliding stability coefficients meet the requirements of regulatory documents.

Table 3. Sliding stability coefficients

\begin{tabular}{|c|c|c|c|c|c|}
\hline \multirow{2}{*}{ № } & Description & $\begin{array}{c}\text { Crest el., } \\
\mathrm{m}\end{array}$ & $\begin{array}{c}\text { Upstream } \\
\text { water } \\
\text { level, } \mathrm{m}\end{array}$ & $\mathrm{K}_{\text {st }}$ & $\mathrm{K}_{\text {norm }}$ \\
\hline 1 & Construction, stage 5 & 1050.00 & 1040.00 & $\mathbf{1 0 , 5 6 8}$ & $\mathbf{1 , 1 8 8}$ \\
\hline 2 & Construction, stage 6 & 1070.00 & 1040.00 & $\mathbf{1 2 , 2 8 0}$ & $\mathbf{1 , 1 8 8}$ \\
\hline 3 & Construction, stage 7 & 1090.00 & 1040.00 & $\mathbf{1 3 , 7 1 6}$ & $\mathbf{1 , 1 8 8}$ \\
\hline 4 & Construction, stage 8 & 1090.00 & 1088.00 & $\mathbf{4 , 5 1 7}$ & $\mathbf{1 , 1 8 8}$ \\
\hline 5 & Construction, stage 9 & 1110.00 & 1088.00 & $\mathbf{4 , 9 1 0}$ & $\mathbf{1 , 1 8 8}$ \\
\hline 6 & Construction, stage 10 & 1130.00 & 1088.00 & $\mathbf{5 , 2 1 1}$ & $\mathbf{1 , 1 8 8}$ \\
\hline 7 & Construction, stage 11 & 1130.00 & 1118.00 & $\mathbf{3 , 2 1 2}$ & $\mathbf{1 , 1 8 8}$ \\
\hline 8 & Construction, stage 12 & 1150.00 & 1118.00 & $\mathbf{3 , 3 4 2}$ & $\mathbf{1 , 1 8 8}$ \\
\hline 9 & Construction, stage 13 & 1150.00 & 1133.00 & $\mathbf{2 , 7 3 2}$ & $\mathbf{1 , 1 8 8}$ \\
\hline 10 & Construction, stage 14 & 1170.00 & 1133.00 & $\mathbf{2 , 7 9 0}$ & $\mathbf{1 , 1 8 8}$ \\
\hline 11 & Main operating case, NWL & 1170.00 & 1166.00 & $\mathbf{1 , 8 2 4}$ & $\mathbf{1 , 2 5 0}$ \\
\hline 12 & Special case, HWL & 1170.00 & 1168.00 & $\mathbf{1 , 7 8 6}$ & $\mathbf{1 , 1 2 5}$ \\
\hline 13 & Special, design disfunction of the grout & 1170.00 & 1166.00 & $\mathbf{1 , 7 5 5}$ & $\mathbf{1 , 1 2 5}$ \\
\hline & curtain and drainage & & & & \\
\hline
\end{tabular}

Assessment of concrete dam stability in displacement using dynamic analysis by finite element method has its own peculiarities. The main criterion for unconditional stability of the structure is the assessment of the trend towards stabilization of displacements and deformations in the time domain. If displacements and deformations in the "structure-base" contact zone stabilize, the structure as a whole can absorb a given impact. When performing computational studies of seismic stability using dynamic theory, stable 
convergence of the problem is obtained, which indicates the ability of the dam to absorb the specified loads.

The analytical method of calculating shear stability does not consider the time factor (rapidity) of the dynamic process, but considers the seismic forces acting on the structure as constant, long-term ones (ST static theory). The seismic force determined for a structural element $\mathrm{k}$ is calculated by formula (15):

$$
P_{k}=k_{f} \cdot m_{k} \cdot \ddot{U}_{0}
$$

where: $\ddot{U}_{0}$ - earthquake acceleration of the foundation; $m_{k}$ - mass of the construction element $\mathrm{k} ; k_{f}$ - coefficient dependent on seismic deformation rate, $k_{f}=0,45$.

First and foremost, 4 pairs with peak accelerations were selected on a given twocomponent accelerogram. Then, the inertial forces (considering the attached water mass) were calculated using formula (15). The calculation results are presented in Table 4.

The sliding stability coefficients calculated from the acceleration pairs of the accelerogram using the ST methodology exceed the normative coefficients in accordance with the building codes of the Russian Federation and the Republic of Uzbekistan [3,4].

Table 4. Sliding stability coefficient by accelerogram peak accelerations

\begin{tabular}{|c|c|c|c|c|c|c|}
\hline \multirow{2}{*}{ № pair } & \multicolumn{2}{|c|}{ Accelerations } & \multicolumn{2}{|c|}{$\begin{array}{c}\text { Stability coefficient } \\
k_{f}=0,45(\mathrm{SP} \\
358.1325800)\end{array}$} & \multicolumn{2}{|c|}{$\begin{array}{c}\text { Stability coefficient } \\
\mathrm{K}_{1}=0,25(\mathrm{SHNK} 2.06 .11)\end{array}$} \\
\hline & $\mathrm{A}_{\mathrm{x}}, \mathrm{m} / \mathrm{s}^{2}$ & $\begin{array}{l}\mathrm{A}_{\mathrm{y}} \\
\mathrm{m} / \mathrm{s}^{2}\end{array}$ & $\begin{array}{c}100 \% \\
\text { contact } \\
\text { surface }\end{array}$ & $\begin{array}{c}50 \% \text { contact } \\
\text { surface }\end{array}$ & $\begin{array}{l}100 \% \\
\text { contact } \\
\text { surface }\end{array}$ & $\begin{array}{l}50 \% \text { contact } \\
\text { surface }\end{array}$ \\
\hline 1 & $-3,6089$ & $\begin{array}{c}- \\
0,3361\end{array}$ & 1,199 & 1,122 & 1,416 & 1,326 \\
\hline 2 & 2,8377 & 0,8972 & 1,258 & 1,175 & 1,464 & 1,370 \\
\hline 3 & $-1,0259$ & $\begin{array}{c}- \\
1,6066\end{array}$ & 1,482 & 1,381 & 1,623 & 1,516 \\
\hline 4 & $-1,3595$ & 1,9473 & 1,401 & 1,304 & 1,571 & 1,467 \\
\hline $\begin{array}{l}\text { ABS } \\
\text { MAX }\end{array}$ & 3,6089 & 1,9473 & 1,111 & 1,034 & 1,359 & 1,269 \\
\hline \multicolumn{3}{|c|}{ Normative coefficient } & \multicolumn{2}{|c|}{1,0625} & \multicolumn{2}{|c|}{1,125} \\
\hline
\end{tabular}

Shear stability using the ST method on peak accelerations of the accelerogram is ensured. At the second stage, the seismic forces were obtained from the dynamic calculation for a given accelerogram and scaled with $k_{f}$ and $\mathrm{K} 1$ coefficients.

According to the calculation results according to the Russian Federation standards $[4,20]$, the minimum factor of stability reserve at full contact "structure-base" was 1.184 , and at the loss of adhesion on $50 \%$ of the contact area 1.108 . Stability ensured.

According to the calculation results according to the building codes of the Republic of Uzbekistan [3,19], the minimum factor of stability in full contact "structure-base" was 1.407 , and at loss of adhesion on $50 \%$ of the contact area 1.317 . Stability ensured.

\section{Conclusions}

As part of the study, a two-dimensional mathematical model of the system "rolling concrete dam - foundation" was developed, which considers the nonlinear behavior of concrete and foundation rocks. The developed mathematical model was used to calculate the stress-strain state under the main and special (seismic effect of maximum designed earthquake) combinations of loads. The calculations are performed in a unified time scale and consider 
the full history of erection and loading of the structure. The calculations of the stress-strain state were performed by the finite element method using the implicit time scheme proposed by Newmark.

As input data for seismic impact modeling were used accelerograms of calculated seismic impact from the nearest zone with probability not exceeding 84\% (maximum design earthquake).

After seismic impact of the maximum design earthquake, extensive zones of plastic deformations arise in the body of the dam. The formation of the through zone of horizontal cracks can lead to unfavorable filtration processes, in this regard, the project initially provides for the device of impervious element - a geocomposite liner on the upstream face.

According to the results of the calculation it can be concluded that in the process of seismic effects of the maximum design earthquake of 9 points magnitude, in the structure may occur significant damage, while there is no progressive growth of movements and deformations in the structure, which indicates the ability of the structure to absorb a given level of loads.

Sliding stability is ensured in case of seismic exposure of 9 points magnitude.

Results of calculations allow to conclude about possibility of construction of Pskem HPP dam made of low cement content concrete.

\section{Acknowledgements}

The Authors express gratitude to Marco Scarella, technical manager of Carpi Tech SA, Carpi Tech $\mathrm{SA}$, for the extensive support while the article was being prepared.

\section{References}

1. ICOLD Bulletin 075. Roller compacted concrete for gravity dams - State of the art (1989).

2. ICOLD Bulletin 117. The gravity dam, a dam for the future (2000).

3. SHNK 2.06.11-04. Construction in seismic regions. Hydraulic engineering structures (2006)

4. SP 358.1325800.2017. Hydraulic structures. Rules of design and construction in seismic-prone regions (2018)

5. SP 20.13330.2016. Loads and actions (2017)

6. ICOLD Bulletin 137. Reservoirs and seismicity (2011)

7. ICOLD Bulletin 135, 2010, Geomembrane sealing systems for dams (2010)

8. Giroud J. P. Leakage Control using Geomembrane Liners. Soils and Rocks. Vol. 3 (2016)

9. Kalpakci V., Bonab A.T., Ozkan M.Y., Gulerce Z. Experimental evaluation of geomembrane/geotextile interface as base isolating system. Geosynthetics International. Vol. 25 (2018)

10. M. Sekulovich. Finite element method (1993)

11. ANSYS, Inc. Theory Reference. Release 19.2

12. Midas GTS NX. User's Guide. MIDAS Information Technology Co. Ltd.

13. ICOLD Bulletin 107. Concrete dams - control and treatment of cracks (1997)

14. SP 40.13330.2012. Concrete and reinforced concrete dams (2013)

15. KMK 2.06.05-98. Dams from unpaved materials. With Amendment No.1 (1998) 
16. K.S. Zavriev, A.G. Nazarov, Y.M. Yzenberg. Fundamentals of the theory of earthquake resistance of buildings and structures (1970)

17. L.N. Rasskazov, G.A. Vorobev, V.V. Malakhanov, A.I. Glazov, N.A. Aniskin. Hydrotechnical structures, Moscow State University of Civil Engineering (2011)

18. B. Bolt. Earthquakes (1981)

19. KMK 2.06.01-97. Hydraulic engineering structures. Basic principles of designing (1997)

20. SP 58.13330.2019. Hydraulic structures. Basic statements (2020). 